\title{
Orientation to Happiness as Predictor of University Students' Engagement
}

\author{
Maria Fernanda Durón-Ramos ${ }^{1}$, Fernanda García-Vázquez ${ }^{2}$ \\ ${ }^{1}$ Department of Pshycology, Instituto Tecnológico de Sonora, Mexico \\ ${ }^{2}$ Department of Education, Instituto Tecnológico de Sonora, Mexico
}

\begin{tabular}{l}
\hline \hline Article Info \\
\hline Article history: \\
Received Sep 8, 2018 \\
Revised Oct 2, 2018 \\
Accepted Oct 16, 2018 \\
\hline Keyword: \\
Eudaimonic \\
Hedonic \\
Orientation to happiness \\
Students' engagement \\
Well-being \\
\hline
\end{tabular}

\begin{abstract}
There is empirical evidence for a close link between positive personal components and students' engagement in academic activities. Personal wellbeing is a construct that can be studied from a variety of angles. Recent studies point to the relevance of orientation to happiness examining three types of well-being. The main objective of this study was to test the relationship that orientation to happiness has with university students' engagement at a public institution in northern Mexico. A stratified probabilistic sample of 266 students was employed. The internal consistency of the scales was analyzed using the SPSS package and a model of structural equations in the EQS program. Results indicated direct and significant relationship between the orientation to happiness and the students' engagement. This supports the importance of promoting positive factors in students to improve their academic and personal development.
\end{abstract}

Copyright (C) 2018 Institute of Advanced Engineering and Science. All rights reserved.

\section{Corresponding Author:}

Maria Fernanda Durón-Ramos, Department of Pshycology, Technological Institute of Sonora Guaymas, Sonora, Mexico.

Email: maria.duron@itson.edu.mx

\section{INTRODUCTION}

The academic performance of university students is a primary indicator of success in the current educational reality, which may account for the increasing number of studies that performance. According to Castaño and Páez, however, it is also important to investigate the relationship between academic performance and the emotional states of these students[1].

In the literature, academic performance is usually measured quantitatively [2]. However, Moroco et al. present the students' engagement construct as an alternative variable for the study of university students' performance [3].

Student engagement can serve to prevent low academic performance, dropout and other negative factors for students in higher education [3]. This engagement is defined by Fredricks et. al [4] as the willingness of students to participate in institutional activities and is formed by three dimensions: behavior, emotion, and cognition.

Academic performance is determined by multiple factors, however, three main categories are often identified: institutional, social, and personal characteristics [5], [6]. This research focuses on personal factors [7]. Peterson et al. [8], claim there is an "orientation to happiness" that includes 3 types of well-being: the hedonic or life of pleasure, the eudaimonic well-being or life of meaning and the flow or life of engagement.

The main objective of the study was to determine the relationship between orientation to happiness and university students' engagement of a public higher education institution in Sonora, Mexico. 


\subsection{University Students' Engagement}

Academic achievement is commonly measured as a function of number of degrees, certificates or qualifications obtained [9], [10]. A number, however, does not fully determine the student's commitment to the academic activities of their institution. Thus, the study of academic performance can be misinterpreted by focusing only on one number or rating [11].

Moroco et al. [3] suggest studying the factor called students' engagement, defined as the willingness of students to participate in academic activities [4], [12], [13]. It is also important to highlight the need to study student engagement in a holistic way.

There are three types of engagement in the university student [3]. Behavioral commitment is the active participation or action of students in academic and extracurricular activities of the university. Emotional commitment is the positive and negative reactions that occur in the school context, directed to either people or situations. Finally, cognitive commitment includes the processes that are involved in the student's learning, that is, those thoughts that encourage the actions of the students.

\subsection{Orientation to happiness}

The literature presents various ways of approaching personal well-being. In general terms, it can be defined as emotions of happiness, satisfaction with life and personal growth [14]. In the present research, it was decided to work specifically on orientation to happiness, where three different types of wellbeing are presented. First, the two classic facets of well-being, the hedonic and the eudaimonic, complemented by the third component based on flow theory [8].

Hedonic well-being is the sum of moods, feelings, and sensations related to the pleasure of an individual [15]. This well-being is not a "final goal". It is rather the process that individuals generate on a daily basis, where positive and negative experiences are engaged. In general, hedonic well-being is related to favorable short term experiences in the individual [16].

Eudaimonic well-being has its foundation in the meaning of life and goes beyond mere transient happiness [17]. It is a process that receives positive rewards in the long term, since it focuses on individual development. It produces the impression that all talents and abilities are improved, and that they serve as a basis for the realization of good things in one's own life or that of others [18].

Finally, the well-being of flow is determined by the individual, since it comes from an activity that, when carried out, produces positive sensations in the subject that may even alter their spatiotemporal perception. These actions may be related to arts, sports, work, etc. This type of well-being depends on each subject. Some can find positive states when engaged in activities that do not generate positive states in others and may even generate negative feelings. There is empirical evidence of the relationship between flow and exceptional work performance [19].

The close relationship that exists between the two facets of well-being continues to be demonstrated in recent studies. According to Gallagher et al. [20] there is a close correlation between hedonism and emotions related to eudaimonic well-being in both adults and university students. In addition, recent theories establish the link between these two types of well-being and positive emotions from the flow [21].

\section{RESEARCH METHOD}

\subsection{Participants}

The sample was stratified probabilistically, taking into account a reliability of $95 \%$ and an error of $6 \%$, with a total of 266 students drawn from all career tracts taught at the Technological Institute of Sonora, Guaymas unit (Table 1), including the municipalities of Empalme and Guaymas. They are 51\% female and $49 \%$ are male. The average age reported was $20.38(\mathrm{SD}=2.76)$. Majority $(92 \%)$ reported being a regular student when participating in the research.

\subsection{Instruments}

To evaluate orientation to happiness, the Spanish version by Durón et al. [22] of the original scale in English from Peterson et al. [8] was used. It contains 18 items divided equally into 3 subscales to assess hedonic well-being, eudaimonic well-being, and flow. The answers were given using a Likert-type scale (Completely opposed to me up to Very similar to me). The authors reported acceptable levels of reliability (.61-.82) in each of the components, as well as a confirmatory factor analysis to establish the validity of the instrument.

The students' engagement was evaluated using the Spanish version of the USEI (University Student Engagement Inventory) of Durón et al. [23]. It consists of 15 items and is divided into cognitive, affective and behavioral dimensions, each composed of five items. Participants could respond using a Likert-type scale with options from never to always. According to analyzes presented by authors, the instrument is valid in the 
Mexican population, with a good internal consistency in each component $(.70-.75)$. Confirmatory factor analysis indicates that the three factors belong to the same construct.

\subsection{Procedure and Data Analysis}

The number of participants for the probabilistic sample was established with $95 \%$ reliability and $6 \%$ error. Then the number of participants was divided proportionally using the percentage of students in each career track. Subsequently, the instruments were applied individually or in groups, depending on the participants. A database was established using the SPSS and EQS programs where the students' answers were recorded.

For the analysis of the data, the internal consistency of the scales was first verified, and then an index was computed for each variable using the mean, after which the descriptive statistics of the two variables with their components were analyzed. Using the EQS program, a Model of Structural Equations was made to test the relationship between happiness orientation and academic performance [24]; This statistical procedure was chosen to avoid the bias that could arise due to the variables that were not retaken within the present investigation. It is decided to use the scquared multiple correlation $R^{2}$ to estimate the influence that Orientation to Happiness has on the university student's engagement [25].

\section{RESULTS AND ANALYSIS}

The internal consistency and descriptive statistics of the scales are presented on Table 1. It is important to note that both the dimensions and the constructs obtained acceptable reliability indices [24]. In the engagement reported by the students, the three types present very similar means, placing themselves in a medium-high range. The orientation to happiness presents response averages that are at a medium-high level as well, in the three well-being areas.

Table 1. Descriptive statistics and reliability of scales and components.

\begin{tabular}{lccccc}
\hline & Min & Max & Mean & $S D$ & Alpha \\
\hline Students' engagement & 0 & 4 & 2.82 & 0.58 & .84 \\
Behavior engagement & 0 & 4 & 2.97 & 0.63 & .72 \\
Emotional engagement & 0 & 4 & 2.82 & 0.74 & .69 \\
Cognitive engagement & 0 & 4 & 2.68 & 0.78 & .76 \\
Orientation to hapiness & 1 & 5 & 3.71 & 0.53 & .84 \\
Hedonic well-being & 1 & 5 & 3.68 & 0.68 & .75 \\
Eudaimonic-Well-being & 1 & 5 & 3.83 & 0.66 & .72 \\
Flow well-being & 1 & 5 & 3.61 & 0.59 & .61 \\
\hline
\end{tabular}

Table 2 displays correlation matrix of the 6 dimentions that constitute the 2 construts of this study. All correlations were high and significant. The factor of university students' engagement has values between .43 and .55 , while the orientation to happiness between .46 and $.56(\mathrm{p}<.01)$. There is also an association between these two constucts, because the components of each are significantly associated with values between .16 and $.42(p<.05)$. This is consistent with other studies in this area [1], [16].

Table 2. Correlation matrix.

\begin{tabular}{|c|c|c|c|c|c|c|}
\hline & $\mathrm{BE}$ & EE & $\mathrm{CE}$ & HW & EW & FW \\
\hline Behavior engagement & 1 & & & & & \\
\hline Emotional engagement & $.50^{* *}$ & 1 & & & & \\
\hline Cognitive engagement & $.55^{* *}$ & $.43^{* *}$ & 1 & & & \\
\hline Hedonic well-being & $.16^{*}$ & $.16^{* *}$ & $.20^{* *}$ & 1 & & \\
\hline Eudaimonic-Well-being & $.42^{* *}$ & $.36^{* *}$ & $.40^{* *}$ & $.54^{* *}$ & 1 & \\
\hline Flow well-being & $.36^{* * *}$ & $.33^{* *}$ & $.38^{* *}$ & $.46^{* *}$ & $.56^{* *}$ & 1 \\
\hline
\end{tabular}

Figure 1 exhibit the model of structural equations where it can be observed that orientation to happiness is a factor composed of the 3 types of well-being, and flow presents the highest factorial weight. The university students' engagement factor was formed by the three types indicated by the theory [3]. There is a positive and significant relationship between the orientation to happiness and the students' engagement, indicating that better conditions of well-being in students can predict the commitment they invest in academic activities, results that agree with findings obtained in similar studies [16], [26].

IJERE Vol. 7, No. 4, December 2018: $294-298$ 


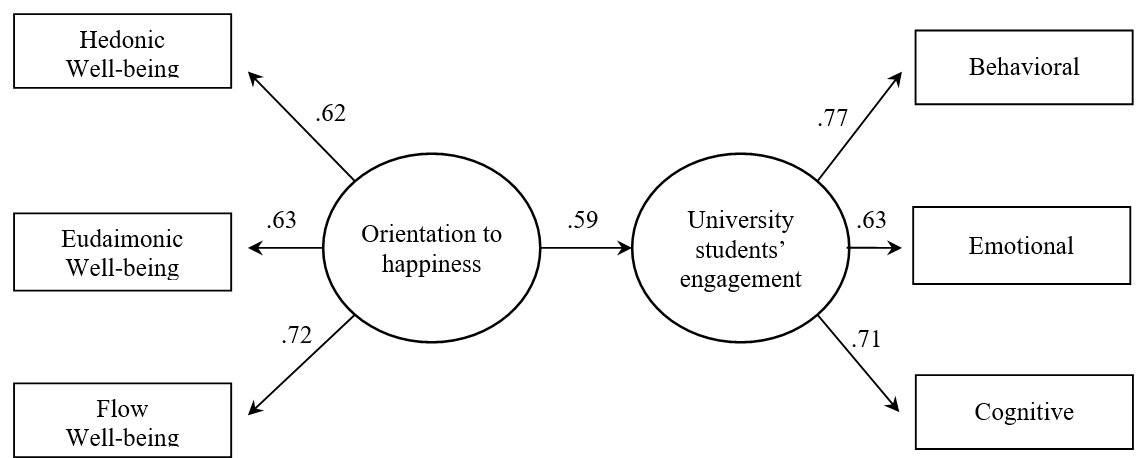

Figure 1. Orientation to happiness and its relation with University students' engagement.

Factorial weights and significant structural coefficients $(\mathrm{p}<.05)$. Goodness of fit: $\mathrm{X} 2=18.67$ (7 GL) $\mathrm{p}$ $<.0005 ; \mathrm{BBNFI}=.95, \mathrm{CFI}=.97 ; \mathrm{IFI}=.97 ; \mathrm{RMSEA}=.079 ; \mathrm{R}^{2}$ University students' engagement $=.35$.

\section{CONCLUSION}

The results obtained emphasize the importance of promoting the development of students in various areas of their lives, not only the academic. This is often promoted in elementary education, but institutions of higher education typically focus primarily on academic issues, the assumption being that a student body composed of adults support in non-academic areas. This research supports the claim that college students perform better when they have positive mental states.

These findings are of great importance because they support the use of strategies to promote wellbeing in university students, not only to help them in their personal performance, but it is a direct support to performance in activities related to their professional training. It is recommended to extend this type of studies in different universities, in order to corroborate the very close relationship that exists between the orientation to happiness and students' engagement.

\section{ACKNOWLEDGEMENTS}

Publication funded with resources from PFCE 2018 (Programa Fortalecimiento de la Calidad Educativa) and Program for the Promotion and Support of Research Projects (PROFAPI 2018).

\section{REFERENCES}

[1] Páez ML, Castaño JJ. "Emotional intelligence and academic performance in university students". Psicología desde el Caribe; 32(2): 268-285, 2015.

[2] Leyva H. "Impacto del uso de instrumentos de evaluación en el rendimiento académico. Caso estudiantes universitarios de la Licenciatura en Turismo". Revista Iberoamericana de Producción Académica y Gestión Educativa. 4(7), 2017.

[3] Maroco J, Maroco AL, Campos JA, Fredricks JA. "University student's engagement: development of the University Student Engagement Inventory (USEI)”. Psicologia: Reflexão e Crítica, 29(1): 21-33, 2016.

[4] Fredricks JA, Blumenfeld PC, Paris AH. "School engagement: Potential of the concept, state of the evidence". Review of Educational Research, 74(1): 59-109, 2004.

[5] Vélez A, Roa CN. "Factors associated with academic performance in medical students". Educación médica, 8(2): 24-32, 2005. [http://scielo.isciii.es/pdf/edu/v8n2/originall.pdf]

[6] Duran P, Vivel M, Maside JM, Lado R. "Analysis of various determinants of academic failure in the degrees of the university of santiago de compostela (USC)”. Proceedings del XI Foro Internacional sobre Evaluación de la Calidad de la Investigación y la Educación Superior. Bilbao-España: 1-6.

[7] Herrera L, Buitrago RE, Peradones TM. "Positive psychology and emotional inteligence on education". Dedica. Revista de Educação e Humanidades, 8:139-153; 2015.

[8] Peterson C, Park N, Seligman E. "Orientations to happiness and life satisfaction: the full life versus the empty life". Journal of Happiness Studies, 6 (1): 25-41; 2005.

[9] Gutiérrez M, Tomás J, Barrica J, Romero I. "Influence of the motivational climate in class on the school commitment of adolescents and their academic achievement". Enseñanza \& Teaching, 35(1): 21-37; 2017.

Orientation to Happiness as a Predictor of University Students' ... (Maria Fernanda Durón-Ramos) 
[10] Meijs N, Cillessen A, Scholte R, Segers E, Spijkerman R. "Social Intelligence and Academic Achievement as Predictors of Adolescent Popularity". Journal Youth Adolescence, 39: 62-72; 2010.

[11] De Miguel CR. "Family factors linked to poor performance". Revista Complutense de Educación, 12(1): 81-113; 2001.

[12] Nystrand M, Gamoran A. "Instructional discourse, student engagement, and literature achievement". Research in the Teaching of English, 25(3): 261-290; 1991.

[13] Reschly AL, Christenson SL. "Jingle, jangle, and conceptual haziness: Evolution and future directions of the engagement construct". In: Christenson S, Reschly A, Wylie C. Eds. Handbook of Research on Student Engagement, USA, Boston. Springer 2012; pp. 3-19.

[14] Vallerand R. "The role of passion in sustainable psychological well-being". Psychology of Well-Being: Theory, Research and Practice, 2(1); 2012.

[15] Fierro A. "Personal well-being, social adaptation and personality factors: studies with the edudemon scales". Revista Clínica y salud, 17 (3): 297-318; 2006.

[16] Durón MF, García FI, Zuñiga MI. "Orientation to happiness and academic performance in university students: Empirical study in ITSON campus Guaymas". In: Pizá RI, Cabrera MJ, Orduño BE Eds. Estimaciones en el Aprendizaje en la Formación Profesional. México: Instituto Tecnológico de Sonora 2017; pp. 108-120.

[17] Ryan R, Deci E. "On Happiness and Human Potentials: A review of research on hedonic and eudaimonic wellbeing". Annual Reviews Psychology, 52(1): 41-66; 2001.

[18] Fernández O, Muratori M, Zubieta E. "Eudaimonic well-being and emotional and social loneliness". Boletín de Psicología, 108: 1-23; 2013.

[19] Dubreuil P et al. "Facilitating well-being and Performance through the Development of Strengths at Work: Results from an Intervention Program”. International Journal of Applied Positive Psychology, 1 (1-3): 1-19; 2016.

[20] Gallagher MW, Lopez SJ, Preacher KJ. "The Hierarchical Structure of Well-Being". Journal of personality, 77(4): 1025-1050; 2009.

[21] Noble T, McGrath H. "PROSPER: A New Framework for Positive Education". Psychology of Well-Being. 5(2): 2$17 ; 2015$.

[22] Durón MF, García FI, Gálvez MK. "Translation and validation of a scale to measure orientation to happiness in Mexican population”. Revista Mexicana de Psicología 2016; Memorias del Congreso Mexicano de Psicología: 2016; 468-469.

[23] Durón MF, García FI, Rodríguez JE y Rodríguez D. "Translation and validation of the university student's engagement inventory in the Mexican population". In press. Wimb $L u 13$ (2).

[24] Corral V, Frías M, González D. “Análisis cuantitativo de variables latentes”. Hermosillo, Sonora: Universidad de Sonora; 2001.

[25] Bentler PM. EQS6 Structural Equations Program Manual. Encino, CA: Multivariate Software Inc.

[26] Salanova M, Martínez IM, Esteve EB, Gumbau SL. "Psychological well-being in university students: facilitators and impeding academic performance". Anales de Psicología, 21(1): 170; 2005.

IJERE Vol. 7, No. 4, December 2018: $294-298$ 